DOI: $10.17805 /$ zpu.2020.1.16

\title{
Изучение искусства как образовательный сценарий XXI века
}

\author{
А. Р. КОЖАРИНОВА \\ МОСКОВСКИЙ ГУМАНИТАРНЫЙ УНИВЕРСИТЕТ
}

В статье анализируются новые образовательные сценарии, связанные с фундаментальными изменениями культуры в XXI в. Открытия в биоинженерии могут привести к тому, что человек впервые в своей истории столкнется с изменениями своей телесности, что создаст платформу для актуализации главного онтологического вопроса: «Кто я и какова моя природа?» Это приведет к обострению проблемы идентичности, причем человека будущего. Трагический разрыв человека со своим субстанциональным образом неизбежно породит стремление к партиципации, понимаемой автором как восстановление собственной экзистенциальной самотождественности.

Поиск путей партиципации инструментально основан на типологии культур А. Моля, который выделял рациональную, системную «гуманитарную» культуру и «мозаичную» культуру поверхностную и случайно выстроенную. Для носителя гуманитарной культуры базисной являлась способность смотреть на мир «синтетически», т. е. видеть объекты и явления целиком. Практики работы с информацией представителя мозаичной культуры стали преимущественно аналитическими, что усугубляет отчуждение человека от самого себя.

В отличие от «индустриального» образования, нацеленного на формирование научной картины мира, образование XXI в. должно быть дополнено изучением искусства, которое инициирует творческую работу с целостными, гармоничными образами и восстанавливает необходимое представителю мозаичной культуры синтетическое видение мира. Автор делает вывод, что изучение искусства сможет помочь человеку, попадающему в точку психологической и экзистенциальной бифуркации, сохранить свой субстанциональный образ. Ключевые слова: искусство; субстанциональный образ человека; идентичность; партиципация

\section{ВВЕАЕНИЕ}

Б удущее человечества, стоящего на пороге колоссальных технологических и социальных перемен, не только вызывает профессиональный интерес футурологов, технологических архитекторов и ученых-гуманитариев, но и волнует и обычных людей. Никто из представителей традиционного общества не сталкивался на протяжении своей жизни со столь радикальными трансформациями экономики, политики, социальной сферы, способов хозяйствования, коммуникации и т. А. - все развивалось медленно и было в достаточной степени предсказуемо. Значимым был принцип детерминизма; флуктуации общественной системы воспринимались как ошибки, а не закономерности.

Сегодня все, что окружает человека, стало чрезмерно сложным. По всей вероятности, XXI в. принесет человечеству еще большие фундаментальные изменения всех жизненных структур, и это будут те изменения, которые мы в настоящее время не можем не только анализировать, но и даже прогнозировать с достаточной точностью. Какими станут технологии? Будет ли развитие нашей цивилизации устойчивым? Как, в конце концов, изменятся наше тело и продолжительность жизни? Можно ли подготовиться к «постчеловеческому будущему» (Ф. Фукуяма)? Тенденции изменения окружающей нас реальности уже намечены и вынуждают нас выстраивать собственные жизненные стратегии в состоянии столкновения с вызовами сложности и неопределенности.

В данной статье обратим внимание только на один из аспектов разнообразных футурологических прогнозов. Развитие биоинженерии, генетики, хирургии расши- 
ряет наши биологические возможности и открывает перспективы по искусственному изменению человека: не только его внешнего вида, но и анатомии, скелета, работы внутренних органов, а также его когнитивных возможностей и продолжительности жизни. Р. Курцвейл, утверждает, что превалирующая ранее доля биологического в человеке к середине XXI в. будет снижаться, пока в конце концов не потеряет свое значение 1 . Таким образом, ожидается изменение самой природы человека как чего-то устоявшегося и инвариантного по отношению к различным историческим типам культур. Представляется, что даже если изменения будут не столь радикальны, как предполагают футурологи, то к чему-то подобному нам все-таки предстоит начинать готовиться. И тут человечество попадает в точку психологической бифуркации: «...впервые в истории человечества возникает реальная опасность разрушения той биогенетической основы, которая является предпосылкой индивидуального бытия человека и формирования его как личности» (Степин, 2000: 32).

Аействительно, представители всех прежних типов культуры точно знали, что если образ их жизни и изменится, то они сами (их физиологической устройство, продолжительность жизни и ее устойчивая стадиальность) останутся константой по отношению к любым внешним трансформациям. Новейшие открытия в биоинженерии, встраиваемые в тело нейрокомпьютерные интерфейсы «мозг-компьютер», замены внутренних органов кибернетическими устройствами лучшего качества, перенесение части жизни в виртуальную реальность и многие другие достижения науки создают платформу для изменения характера проблем, с которыми столкнется человек недалекого будущего: новации актуализирует главный онтологический вопрос: «Кто я?»

Известные в прошлом ответы - «Я - это мое тело», «Я - это мой ум», «Я - это моя память», «Я - это мои чувства» и даже «Я - это пустота, ничто» - в эпоху постсовременности станут уязвимыми и, вероятно, перестанут нас удовлетворять. Аругими словами, мы столкнемся с «крахом субстанционального образа человека» (Иеонтьев, 2007). Подобные изменения приведут обострению проблемы идентичности. Причем, если вопросы сохранения (обретения) социальной и личной идентичности интересовали человека во все времена, то человек будущего, вероятно, сосредоточится на онтологических, видовых, экзистенциальных, физиологических аспектах идентичности. Разрыв человека со своим субстанциональным образом неизбежно будет мучителен, приведет к шоку отчуждения от самого себя и, как следствие, породит стремление к партиципации, понимаемой нами как механизм восстановления экзистенциальной самотождественности, «экзистенциальное природнение» ${ }^{2}$ к самому себе.

\section{ТРАНСФОРМАЦИЯ ПРАКТИК РАБОТЫ С ИНФОРМАЦИЕЙ КАК ТАКТИКА ПАРТИЦИПАЦИИ}

Предлагаемая в статье попытка поиска путей партиципации инструментально основана на типологии культур А. Моля, который в работе «Социодинамика культуры» выделяет традиционную «гуманитарную»и новую «мозаичную» культуру (Моль, 2008). Гуманитарная культура основана на иерархии существенного и менее важного в окружающих человека идеях, что фиксируется в общих и второстепенных понятиях. Роль культуры, по А. Молю, «состоит в том, что она дает человеку “экран понятий”, на который он проецирует и с которым он сопоставляет свои восприятия внешнего мира» (там же: 46). В традиционной культуре «экран понятий» имеет геометрически правильную сетчатую, т. е. рациональную структуру, по кото- 
рой человеку без труда удавалось определять сложные понятия через более простые или более общие, переходить от одного понятия к другому, связывая их между собой в единую смысловую целостность. Такой метод познания мира был по сути своей картезианским, построенным на формальных рассуждениях. Представитель гуманитарной культуры двигался от одного узла сети знаний к другому, увеличивая количество переплетений и связывая их воедино. Ткань знаниевой сети уплотнялась и упрочнялась в результате получения фоновых знаний, обучения дома, но более всего - в процессе получения образования. Построенная структура была крепкой, рациональной и «экономно построенной» (там же).

В западноевропейской цивилизации во второй половине XX в. наблюдается закат гуманитарной культуры. Современный «экран понятий» представляет «массу волокон, сцепленных как попало, - длинных, коротких, толстых, тонких, размещенных почти в полном беспорядке» (там же), т. е. идейная субординация в нем нарушена. Сообщения, внедряющиеся в сознание индивида, разрозненны, не иерархически выстроены, связаны ассоциативно. Картина мира формируется представителем такой культуры статистически, «методом проб и ошибок». «Экран знаний» становится похож на волокнистое образование, подобное войлоку. Обрывки идей, несмотря на свою разрозненность, обладают силой сцепления, которая, как и в гуманитарной культуре, придает «экрану знаний» определенную плотность, но рациональной конструкции такой экран не образует: в нем отсутствуют многие обобщающие понятия, точки отсчета, не выстраиваются связи. К тому же, как в калейдоскопе, мозаика постоянно меняется - старые волокна замещаются новыми, одни связи сменяются Аругими, ценность элементов из «экрана знаний» варьируется. Индивид непрерывно поглощает множество хаотических отрывочных сведений, оставаясь при этом на поверхности смыслов. Это приводит к тому, что «человек находится в постоянном разладе с интеллектуальным миром, который он сам для себя создал» (там же: 216). А. Моль отмечает, что мозаичная культура является продуктом воздействия не системы образования, а средств массовой информации.

Итак, пространство существования гуманитарной культуры (рациональной и систематизированной) сужается, на смену приходит конфликтующая с ней мозаичная культура (поверхностная и случайно выстроенная).

Проанализируем практики работы с информацией, характерные для представителей обеих культурных типов.

Аля носителя гуманитарной культуры привычной являлась работа с целостными образами, что вырабатывахо у него способность смотреть на мир синтетически, а на самого себя - в совокупной полноте собственных проявлений. Истоком синтетического взгляда на мир была мифологическая картина мира, связывающая объекты мироздания случайными эмпатическими и иерархически выстроенными связями. Взаимодействие с целостными мифологическими образами не расщепляло синкретичное сознание первобытного или античного человека, а, напротив, помогало ему ощутить связь всего со всем, что облегчало адаптацию к миру природы и к миру культуры, ситуативно выстраивало идентичность субъекта. Синтетический тип мышления не только формировал способность видеть явления целиком, но и уменьшал страх от столкновения с неопределенностью.

Мозаичная культура основана на дифференцированном взгляде на объекты «волокнистого» мира и, как следствие, «расщеплении» самого образа человека. Практики работы с информацией представителя мозаичной культуры стали преимущест- 
венно аналитическими, под которыми в данном случае будем понимать практики, связанные с мышлением, склонным разбивать получаемую информацию на отдельные составляющие и поэтапно эти составляющие осваивать. При столкновении с проблемой субъект-«аналитик» ищет оптимальный из уже известных способов ее решения, а не находя - демонстрирует плохую переносимость непредсказуемости и неопределенности. Хаотичность и сингулярность актов описания любых объектов все больше подчиняется закону случайности: субъект не видит диалектических взаимосвязей, не понимает причинности и т. п. Подобный взгляд вовне не может не начать довлеть над человеком, который начинает смотреть аналитически на собственную самость, что в условиях мозаичной культуры еще больше разрушает его партиципационные связи и подрывает субстанционахьный базис.

Аумается, что для психики современного субъекта, уже сегодня застревающего в ситуации тотальной непредсказуемости и неопределенности, синтетические практики работы с информацией и объектами окружающего мира гораздо «терапевтичнее», чем аналитические, а в будущем - именно такой взгляд на мир сможет помочь человеку сохранить онтологические основания собственной целостности, ослабить шок от описанных выше трансформаций. Поэтому, наряду с безусловно необходимым аналитическими познавательными программами, нами не должна утрачиваться способность видеть мир синтетически. Представляется, что программа реабилитации «синтетического» взгляда на мир реанимирует ощущение причастности к Бытию и к сформированному гуманитарной культурой собственному субстанциональному образу, может стать импульсом к преодолению собственной «расколотости», обрести экзистенциальную идентичность.

\section{ИЗУЧЕНИЕ ИСКУССТВА: ОТ ПЕРИФЕРИИ К ЦЕНТРУ}

Попытаемся далее описать адекватные предстоящим вызовам образовательные траектории и алгоритмы, которые следовало бы начать выстраивать сегодня, чтобы завтрашние кардинальные изменения не застали человечество врасплох.

Качеством, которым человеку «эпохи неопределенности» жизненно важно обладать, является креативность. В отличие от «индустриального» образования, в котором творческая природа чаще всего нивелируется, образование XXI в. уже начинает придавать творческой деятельности обучающегося особенное социально-культурное и нравственное измерение. Подчеркнем, что под креативностью в широком смысле поднимается не только деятельность по созданию нового, но и способность принимать нетривиальные решения с использованием нестандартных методов и инструментов, быстро переориентироваться с одного аспекта проблемы на другой, сопротивляться стереотипам, мыслить гибко и небанально, быть чувствительным к противоречивому, новому и необычному.

Особенно отметим, что одним из критериев креативного человека является его склонность к образному, символическому и ассоциативному мышлению, умение видеть (Чикесентмихайи, 2017). Роль искусства, говорящего на разных языках описания реальности, в формировании креативности сложно переоценить. Язык этого вида духовной культуры субъективно воспринимается и переживается читателями, зрителями и слушателями; символы считываются неоднозначно; художественные образы характеризуются недосказанностью и оригинальной творческой манерой их создателей, что инициирует у столкнувшегося с искусством человека поток эмоций, связанный с желанием разгадать замысел автора. Все это располагает к выстраиванию ассоци- 
ативных связей, активности, сотворчеству, в общем - пробуждает экзистенцию. Креативность является одной из важных характеристик самоактуализирующегося субъекта, преодолевающего свою расщепленность и восстанавливающего личные онтологические основания. Итак, акцентирование внимания на творческой природе человека рассматривается нами как категорический образовательный императив.

С парадигмой целостности субстанционального образа человека связан и принцип холизма. Педагоги школы и преподаватели вузов уже сегодня столкнулись с отсутствием у обучающихся системного мышления: рядовой выпускник школы, в основной массе, не умеет рассматривать объекты и явления целиком, учитывать контекст, не то чтобы устанавливать скрытые, но видеть даже явные причинно-следственные связи. Такого индивида не смущают противоречия (он их просто не замечает), от него ускользнет ощущение красоты и стройности объекта и явления.

Напомним, что гармоничность соединения частей целого действительно является важным системообразующим признаком. Исследователи выделяют пять организационных признаков гармоничной системы: единство формы и содержания; внутреннее равновесие системы как совмещение противоположных начал; борьба противоречий; сочетание необходимого и случайного, обеспечивающее, с одной стороны, устойчивость системы, с другой - ее изменчивость и гибкость; внутренняя и внешняя согласованность элементов системы как условие ее әффективного функционирования (Самохвалова, 1998: Электронный ресурс). Гармоничность систем необходимо учить замечать, формировать представление о существовании некоего идеала организации упорядоченности и уравновешенности. Умение анализировать «параметры» гармоничной системы настраивает человека на әстетическое переживание и оценку мира, а эстетично воспитанная душа получает в свое распоряжение метафизическую установку на сродство с Космосом. Подобное самовосприятие интегрирует психофизиологические составляющие человека, налаживает связь между разумом и чувством, внутренним и внешним, индивидуальным и социальным, эгоизмом и альтруизмом, между лево- и правополушарным мышлением и т. п.

Аействительно, осознание мира как гармонично организованного всегда было важной духовной потребностью: эстетически развитый человек эйфорически переживает чувство партиципационной гармонии. Мифы, верования, религии большинства культур описывали мир как изначально красивый и слаженно функционирующий. Грех, напротив, воспринимался как нравственное и эстетическое отторжение гармонии. Безусловно речь не идет о реставрации мифологической картины мира: современными вариациями мифологий и так перенасыщена сегодняшняя культура. Но саму практику работы с целостными образами можно и нужно возродить, а сделать это целесообразно, вводя в образовательный контекст преподавание дисциплин, связанных с искусством, сутью которого является актуализация гармонии (Шестаков, 1983: 179).

Знакомство с принципом единства формы и содержания, раскрытие взаимодействия противоположных эстетических категорий (трагическое - комическое, прекрасное - безобразное, возвышенное и низменное и т. А.), разбор диалектики новых и старых художественных тенденций, установление связи утилитарного и духовного - все это учит человека судить о гармоничности и дисгармоничности, формирует основу для понимания грандиозности мира, переводит человека на экзистенциальный уровень. Изучение искусства может реанимировать синтетическую картину мира, помочь увидеть вовне некое объединяющее начало, способствовать решению проблемы экзистенциальной идентичности. 


\section{ЗАКАЮЧЕНИЕ}

Итак, возникшая в XX в. мозаичная культура способствовала переходу от синтетического взгляда на мир к дробному и препятствующему партиципации - аналитическому. Рост сложности и неопределенности, прогнозируемое обострение проблемы экзистенциальной идентичности требуют усиления внутренних опор человека. Поэтому научная парадигма, на основе которой выстраивалось нацеленное на изучение внешнего «индустриальное» образование, должна быть дополнена изучением говорящего о Бытии искусства, инициирующего творческую работу с целостными, гармоничными образами. Образование, в котором теоретическое и практическое изучение искусства будет смещаться от периферии (на которой оно находится в настоящий момент) к центру, уже сегодня восстановит необходимое представителю мозаичной культуры синтетическое видение мира и станет условием партиципационного единения с самим собой. А в XXI в. не наука, а именно искусство сможет помочь человеку, столкнувшемуся с экзистенциальным шоком будущего, сохранить свой субстанциональный образ.

\section{ПРИМЕЧАНИЯ}

${ }^{1}$ Курцвейл Р. (2013) O «постчеловеке» [Электронный ресурс] // Проект мнение. URL : https://mnenie.me/kurcvejl-o-postcheloveke.html (дата обращения: 02.10.2018).

2 Пелипенко А. А. Человек переживающий: экзистенциальные аспекты [Электронный ресурс]// Персональный сайт Андрея Пелипенко. URL: http://apelipenko.ru/Наука/Статьи/Теория культуры/Идентичность.аspх (дата обращения: 15.10.2018).

\section{СПИСОК АИТЕРАТУРЫ}

Аеонтьев, А. А. (2007) Восхождение к экзистенциальному миропониманию // Третья Всероссийская научно практическая конференция по экзистенциальной психологии: материалы сообщений / под ред. А. А. Аеонтьева. М. : Смысл. 188 с. С. 3-12.

Моль, А. (2008) Социодинамика культуры. М. : $\Lambda$ КИ. 416 с.

Самохвалова, В. И. (1998) О метафизическом смысле гармонии [Электронный ресурс] // Культурно-просветительский журнал «Аельфис». № 16 (3). URL: http://www.delphis.ru/journal/article/o-metafizicheskom-smysle-garmonii (дата обращения: 10.10.2018).

Степин, В. С. (2000) Теоретическое знание. М. : Прогресс-Традиция. 744 с.

Чикесентмихайи, М. (2017) Креативность: Психология открытий и изобретений. М. : Карьеpa Пресс. 528 c.

Шестаков, В. П. (1983) Эстетические категории. М. : Искусство. 358 с.

Аата поступления: 25.10.2019 2.

\section{STUDYING ART AS AN EDUCATIONAL SCENARIO OF THE $21^{\text {st }}$ CENTURY \\ A. R. KOZHARINOVA \\ MOSCOW UNIVERSITY FOR THE HUMANITIES}

This article examines new educational scenarios associated with the fundamental changes in culture in the 21st century. For the first time in history, discoveries in bioengineering can lead to the human encountering changes in their corporality, which will create a platform for the actualization of the main ontological question: "Who am I and what is my nature?" This will cause an issue of identity, especially of the man of the future. The disastrous gap between an individual and their substantial image will inevitably give rise to a desire for participation, understood by the author as the restoration of their own existential self-identity.

The search for ways of participation is instrumentally based on the typology of cultures by A. Moles, who singled out a rational, systemic "humanitarian" culture and a "mosaic" culture — su- 
perficial and randomly built. For the bearer of humanitarian culture, the ability to look at the world "synthetically" was basic, which means seeing objects and phenomena in their entirety. The practices of working with information has become primarily analytical for a representative of the mosaic culture, which exacerbates the a person's alienation from themself.

Unlike the "industrial" education aimed at creating a scientific picture of the world, the education in the 21st century should be supplemented by the study of art, which initiates creative work with holistic, harmonious images and restores the synthetic vision of the world essential for representatives of the mosaic culture. The author concludes that the study of art will be able to help a person who reaches the point of psychological and existential bifurcation to maintain their substantial image.

Keywords: art; substantial image of a person; identity; participation

\title{
REFERENCES
}

Leont'ev, D. A. (2007) Voskhozhdenie k ekzistentsial'nomu miroponimaniiu. In: Tret'ia Vserossiiskaia nauchno prakticheskaia konferentsiia po ekzistentsial' noi psikbologii: materialy soobshchenii./ ed. by D. A. Leonteva. Moscow, Meaning. 188 p. Pp. 3-12. (In Russ.).

Moles, A. (2008) Sotsiodinamika kul'tury. Moscow, LKI. 416 p. (In Russ.).

Samokhvalova, V. I. (1998) O metafizicheskom smysle garmonii. Kul'turno-prosvetitel' skii zhurnal Del'fis, no 16 (3/1998). [online] Available at: http://www.delphis.ru/journal/article/ometafizicheskom-smysle-garmonii [archived in WebCite] (accessed 10.10.2018) (In Russ.).

Stepin, V. S. (2000) Teoreticheskoe znanie. Moscow, Progress Tradition. 744 p. (In Russ.).

Csikszentmihalyi, M. (2017) Kreativnost': Psikbologiia otkrytii i izobretenii. Moscow, Career Press. 528 p. (In Russ.).

Shestakov, V. P. (1983) Esteticheskie kategorii. Moscow, Art. 358 p. (In Russ.).

Submission date: 25.10.2019.

Кожаринова Анна Ростиславовна - кандидат философских наук, доцент кафедры философии, культурологии и политологии Московского гуманитарного университета. Адрес: 111395 , Россия, г. Москва, ул. Юности, д. 5. Тел.: +7 (499) 374-55-11. Эл. адрес: anna_adv@inbox.ru

Kozharinova Anna Rostislavovna, Candidate of Philosophy, Associate Professor, Department of Philosophy, Culturology and Politology, Moscow University for the Humanities. Postal address: 5, Yunosti St., Moscow, Russian Federation, 111395. Tel.: +7 (499) 374-55-11. E-mail: anna_adv@ inbox.ru

DOI: $10.17805 /$ zpu.2020.1.17

\section{Вузовская среда и мера воспитанности студентов}

\author{
Б. Ф. УСМАНОВ
}

МОСКОВСКИЙ ГУМАНИТАРНЫЙ УНИВЕРСИТЕТ

В статье представлено авторское мнение о том, какая система ценностей и взглядов нужна образовательным заведениям России, которым Федеральный закон «Об образовании в Российской Федерации", вступивший в силу с 1 сентября 2013 г., вернул функцию воспитания. Автор размышляет: есть ли у нынешней российской системы образования главенствующая идея и как измерять сегодня воспитанность студента. При этом в подтексте вопрос вопросов: для кого (или для чего) учим и воспитываем? 